\title{
Comparative Evaluation of Disease Induced by Three Strains of Tobacco etch virus in Capsicum annuum $\mathrm{L}$.
}

\author{
John F. Murphy and Tolulope Morawo, Department of Entomology \& Plant Pathology, Auburn University, AL 36849
}

\begin{abstract}
Tobacco etch virus (TEV; genus Potyvirus) strains HAT, Mex21, and N were evaluated comparatively for their pathogenicity and effects on growth of Capsicum aпnиит L. 'Calwonder'. Each TEV strain induced an initial systemic symptom of vein-clearing but subsequent disease symptoms ranged from mild (HAT) to moderate (Mex21) to severe (N). Effects on plant growth parameters closely reflected disease symptoms induced by each TEV strain. HAT-infected Calwonder plants did not differ from the healthy control for plant height, internode lengths, and aboveground fresh weight of shoots. Root dry weight, however, was less for HAT-infected plants than for the

healthy control. Mex21 affected plants more severely, with significantly shorter plant height (at 20,30, and 40 days postinoculation), reduced root dry weight, and shortened internodes compared with HAT and healthy control treatments. Aboveground fresh weight of Mex21-infected plants was significantly less than for the healthy control. $\mathrm{N}$ induced significant negative effects relative to each of the other treatments for plant height, aboveground shoot fresh weight, root dry weight, and internode lengths. The effects on Calwonder fruit production mimicked disease severity and effects on plant growth for the respective TEV strains.
\end{abstract}

Tobacco etch virus (TEV) was reportedly first described by Johnson in 1930 (Purcifull and Hiebert 1982). TEV is now a recognized member of the genus Potyvirus, family Potyviridae, which contains the largest number of virus species among the plant viruses (Berger et al. 2005). TEV was shown to occur in North, Central, and South America, as well as in Europe and Asia (CABI 2010). The virus has a moderately wide host range that includes 149 plant species in 19 families (Edwardson and Christie 1997; Shukla et al. 1994), most of which are in the family Solanaceae.

Since 1955, TEV has been a serious threat to the pepper industry in Florida (Anderson and Corbett 1957) and was shown to infect all varieties in a field trial carried out in one Florida county (Ozaki 1963). Zitter (1971) reported a continued widespread occurrence of TEV in South Florida. Pepper fruit yields were reduced 25 to $70 \%$ (Nutter et al. 1989; Rufty et al. 1989), with the potential for greater losses due to the frequent occurrence of coinfections with other viruses (Green and Kim 1991; Roberts et al. 2004).

TEV is a flexuous, rod-shaped particle consisting of a single molecule of single-stranded RNA genome that encodes a polyprotein that is cleaved into approximately 10 individual proteins (UrcuquiInchima et al. 2001). The viral RNA has a protein covalently linked through a tyrosine residue to its $5^{\prime}$ terminus, referred to as the VPg (Murphy et al. 1990, 1991), and a 3' poly (A) tract (Hari et al.1979). The full-length sequence of the TEV genome (HAT strain) was first reported by Allison et al. (1986). The viral RNA consisted of 9,496 nucleotides with a translational product of a 3,054-amino-acid polyprotein. TEV strains HAT, Mex21, and $\mathrm{N}$ have been the focus in previous studies aimed at dissecting important sources of resistance in Capsicum spp. (Kang et al. 2005; Perez et al. 2012). These three strains were shown to differ in their pathogenicity in Nicotiana spp., with TEVHAT inducing mild disease, TEV-Mex21 moderate disease, and TEV-N severe disease symptoms (Velasquez et al. 2015). Their genomes were sequenced and shown to have $98 \%$ nucleotide sequence identity among strains TEV-Mex21 and TEV-N and 91\% nucleotide sequence identity for TEV-HAT with TEV-Mex21 and TEV-N (Velasquez et al. 2015).

Corresponding author: J. F. Murphy; E-mail: murphjf@auburn.edu

Accepted for publication 24 August 2016.

C 2017 The American Phytopathological Society
Despite the importance of TEV as a pathogen of solanaceous crops and the focus on TEV strains HAT, Mex21, and N in genetic studies, a thorough comparative study among the three strains for their effects on pepper plant growth and development has not been reported. In this report and previous preliminary studies (Murphy 2012, 2014), the three TEV strains are shown to induce distinct symptoms in susceptible 'Calwonder' pepper, and a disease gradient that ranges from mild for TEV-HAT to severe for TEV-N. Effects on Calwonder growth and development correspond strongly with disease symptoms of each respective virus.

\section{Materials and Methods}

Viruses, plant growth conditions, and experimental designs. The TEV strains used in this study included TEV-HAT, TEVMex21, and TEV-N. To simplify reference to these viruses, they will be referred to as HAT, Mex21, and N, respectively. HAT was obtained from Dr. Thomas Pirone, University of Kentucky; Mex21 from Dr. Molly Jahn, Cornell University (originally provided by Dr. Lowell Black, Louisiana State University), and N was provided by Dr. Brad Reddick, University of Tennessee. The HAT strain used in this study was the same strain referred to as HAT-AU by Velasquez et al. (2015). Each TEV strain was maintained in Nicotiana tabacum L. 'Kentucky 14' by mechanical passage in a temperature-controlled greenhouse (mean day and night temperatures of 24 and $20^{\circ} \mathrm{C}$, respectively) at the Plant Science Research Center on the campus of Auburn University in Alabama.

For each experiment, Calwonder pepper seed (American Meadows, Williston, VT) was sown in Sunshine Mix number 8 soilless potting medium (Sun Gro Horticulture, Canada Ltd., Sacramento, CA) in 72-well Styrofoam trays (Speedling Inc., Bushnell, FL). Germinated seedlings were transplanted to 3.8-liter round pots, with the exception of those used for the fruit yield study, in which 18.9-liter round pots were used. In all cases, each pot contained a single plant. In experiments conducted to evaluate the effects of the TEV strains on plant growth, with the exception of the root study, Sunshine Mix number 8 was used as a growth medium. For the experiments conducted to evaluate effects of the TEV strains on root growth, plants were grown in a mixture consisting of three parts Sunshine Mix number 8 to one part sand. In all experiments, the growth medium was supplemented with slow-release fertilizer (18-6-12, Osmocote Classic; Scotts Company LLC, Marysville, OH).

For plant growth experiments that evaluated the effects of each TEV strain on Calwonder, virus was applied to leaves 1 and 2 (the two oldest true leaves along the main stem) by rub inoculation when plants were at the seven- to eight-leaf stage of growth (Andrianifahanana 
et al. 1997). TEV strain inoculum consisted of systemically infected 'Kentucky 14' leaf tissue ground in $50 \mathrm{mM}$ potassium phosphate buffer ( $\mathrm{pH}$ 7.5). The mortars, pestles, and buffer used for inoculation were chilled at $4{ }^{\circ} \mathrm{C}$ prior to use and kept on ice during the inoculation process.

To evaluate effects of each TEV strain on pepper fruit yield, Calwonder plants were inoculated at the 9- to 10-leaf stage with virus applied to leaves 1 through 3. As plant size increased, plants were trained on a standard high-wire system (Van de Vooren et al. 1986) using a single 0.48 -cm-diameter cable suspended above each greenhouse bench. Plastic tomato twine was tied to the cable and hung vertically. Plant stems and individual branches were attached to the twine with MG23 clips (Berry Hill Irrigation, Buffalo Junction, VA), adding clips when needed as plants matured.

Each experiment was arranged in a completely randomized design along a bench and included rows of three (18.9-liter pots; yield study) or five (3.8-liter pots; effects on growth study, virus accumulation test) plants, with each row consisting of a single virus treatment or healthy control. The difference in the number of pots per row was due to pot size (i.e., five 3.8-liter round pots versus three 18.9-liter round pots fit as a row on the greenhouse bench).

Plant growth evaluations. Plant height measurements (in centimeters; $n=18$ per treatment per time point) were taken from soilline to the apical tip of the longest stem at 0 (day of inoculation), $10,20,30$, and 40 days postinoculation (dpi). Stem internode lengths (in centimeters; $n=10$ plants per treatment) along the main stem were measured at $35 \mathrm{dpi}$ and included the internode between the hypocotyl and leaf 1 (H-L), leaf 1 to leaf 2 (I1-2), and each consecutive internode up to the internode between leaves 9 and 10 (I9-10). Plant aboveground fresh weight (in grams; $n=12$ per treatment) was taken at 40 dpi. For plant root dry weight (in grams; $n=12$ plants per treatment), roots were carefully rinsed with water to remove Sunshine Mix number 8 and sand, excised from the main stem at the soil line, and allowed to dry at $37^{\circ} \mathrm{C}$ for 5 days, at which time the weight was determined. Plant growth measurements reported herein were taken from a single experiment; additional but separate experiments were performed with similar outcomes. Differences in plant height, aboveground fresh shoot weight, and root dry weight among virus and healthy control treatments were analyzed using one-way analysis of variance (ANOVA) after confirming that data fit the assumptions of ANOVA (parametric test). For each test (plant height, aboveground fresh shoot weight, and root dry weight), means were separated using Turkey's posthoc test.

Virus infection evaluations. The relative accumulation levels of each TEV strain in young developing leaf tissues was determined at different time points throughout the experiment in order to confirm their presence in newly expanding leaves as Calwonder plants continued to grow. Virus detection was by enzyme-linked immunosorbent assay (ELISA) using a TEV-specific commercial kit (Agdia Inc., Elkhart, IN). The ELISA procedure was performed as described previously (Velasquez and Murphy 2014). At 10 and $20 \mathrm{dpi}$, a single noninoculated leaf (representing a systemic infection) was collected from each plant and tested individually for virus accumulation by ELISA. For the 30- and 40-dpi tests, two noninoculated leaves were collected from each plant, then processed as a single sample representing the respective plants. For each time point, comparable leaves were collected among plants within treatments and among treatments. Leaf samples consisted of young, expanded (though not fully) leaves located at the uppermost portion of the plant. This method for leaf collection was followed throughout the experiment; however, at 30 and $40 \mathrm{dpi}$, growth of $\mathrm{N}$-infected plants was severely negatively impacted and "comparable" leaves were difficult to identify due to a lack of upper branch extension. For these $\mathrm{N}$-infected plants, the largest testable leaf near the end of one or more branches was collected for ELISA. At each time point, 20 plants were tested for each TEV strain ( $n=20$ plants per treatment per time point). Leaf samples were processed on a weighted basis of $1 \mathrm{~g}$ of leaf tissue to $5 \mathrm{ml}$ of general extraction buffer (Agdia, Inc.), with $25 \mu \mathrm{l}$ of sap extract added to each microtiter plate well containing $75 \mu l$ of general extraction buffer. Each microtiter plate had three comparable healthy control samples used to determine a threshold for positive detection of virus. The threshold was determined as the mean plus three standard deviations of the healthy control ELISA absorbance values. In an effort to standardize ELISA reactions from one test date to another, each microtiter plate contained two samples of purified HAT of known concentration, and microtiter plate reactions were recorded when the purified sample achieved an absorbance value of approximately 1.0. Differences in ELISA absorbance values of different virus treatments at each sampling date, as well as differences in ELISA absorbance values of each virus treatment at different sampling dates, were analyzed using Kruskal-Wallis test, followed by Bonferroni multiple comparison of rank sums.

Effects on Calwonder fruit production. Pepper fruit was collected when the collar turned red; however, fruit was also collected when associated with broken branches. Fruit yields (count and weight) were determined and graded marketable or nonmarketable according to United States Department of Agriculture standards (USDA 1991).

The deviation of fruit counts from hypothesized equal proportions $(25 / 25 / 25 / 25 \%)$ among the four treatments (three TEV strains and healthy control) was determined using analysis of independence in two-way contingency tables for marketable or nonmarketable fruit counts against virus treatment. An exact $\chi^{2}$ goodness-of-fit test was used because some cell counts were below 5 . Total fruit count (combined marketable and nonmarketable) among the four treatments was also analyzed using an exact goodness-of-fit test. Pairwise comparison was made using a similar test $(50 / 50 \%)$, with Bonferroni adjustment to $P$ value $(\alpha=0.05 / 6=0.0083)$.

For nonmarketable fruit, the difference in fruit weight among treatments was analyzed using the Kruskal-Wallis test (nonparametric). Means were separated using Bonferroni multiple comparison of rank sums of fruit weights. For weight of marketable fruit, only the HAT and healthy control treatments were compared because no samples were available for Mex 21 and $\mathrm{N}$ treatments. Therefore, the difference in fruit weight between HAT and healthy control treatments was analyzed using the Wilcoxon-Mann-Whitney test (nonparametric).

For total fruit yield (combined marketable and nonmarketable), the difference in weight of fruit that weighed $50 \mathrm{~g}$ or more among treatments was analyzed using the Kruskal-Wallis test. The virus treatment, $\mathrm{N}$, was excluded from the analysis because of extremely low sample size.

\section{Results}

TEV strain-induced symptoms. Each TEV strain induced systemic symptoms by $7 \mathrm{dpi}$ and, for each TEV strain, there was a consistent pattern of symptom development. Plants were inoculated at the seven- to eight-leaf stage (leaf 1 being the oldest leaf along the stem) and systemic vein-clearing first appeared on leaves 5 and 6 , and sometimes on leaves 6 to 8 . For some plants, leaf 9 had veinclearing and also developed mosaic symptoms but, in most cases, all leaves above leaf 8 had strain-specific mosaic-type symptoms. HAT induced mild systemic vein-clearing followed, in newly emerging leaves, by mild mosaic symptoms (Fig. 1A). The vein-clearing symptoms were no longer visible 7 to 10 days after their initial appearance. In later stages of the experiments, mosaic symptoms continued to be mild and often difficult to detect, with little or no reduction in overall plant growth (Fig. 1B). Mex21-infected Calwonder plants developed systemic vein-clearing (more obvious than that induced by HAT) that remained visible 10 to 14 days after their initial appearance. The newly emerging leaves expressed a distinct and obvious blotchy mosaic pattern that continued for all newly emerged leaves, including and especially those on branches above the main stem (Fig. 1A). Leaves on branches above the main stem were smaller and, overall, plant growth was stunted relative to healthy control and HAT-infected plants (Fig. 1B). Calwonder plants infected with $\mathrm{N}$ had the most severe symptoms, beginning with systemic vein-clearing similar to but more intense than that induced by Mex21. The $\mathrm{N}$-induced vein-clearing remained visible on some leaves throughout the experiment. Newly emerging leaves had a 
severe chlorotic mosaic symptom or remained green, with little evidence of a clearly defined mosaic pattern; however, in both cases, leaves were small, deformed, and always downward cupped (Fig. 1A). By the end of each experiment, there was only limited extension of secondary and tertiary branches above the main stem, resulting in severely stunted plants (Fig. 1B) having many small, deformed leaves bunched together at the top of the plant, often just above the initial branch point of the main stem. At later times in each experiment, leaves clumped together at the top of $\mathrm{N}$-infected plants were chlorotic, brittle, and downward cupped.

Virus accumulation in systemically infected leaves. The testing of foliar tissues by ELISA for accumulation of each TEV strain was carried out on a weighted basis, thereby allowing a more accurate comparison among virus strains. In addition, the ELISA procedure included known purified virus controls which allowed standardization of the procedure from one sampling date to another.

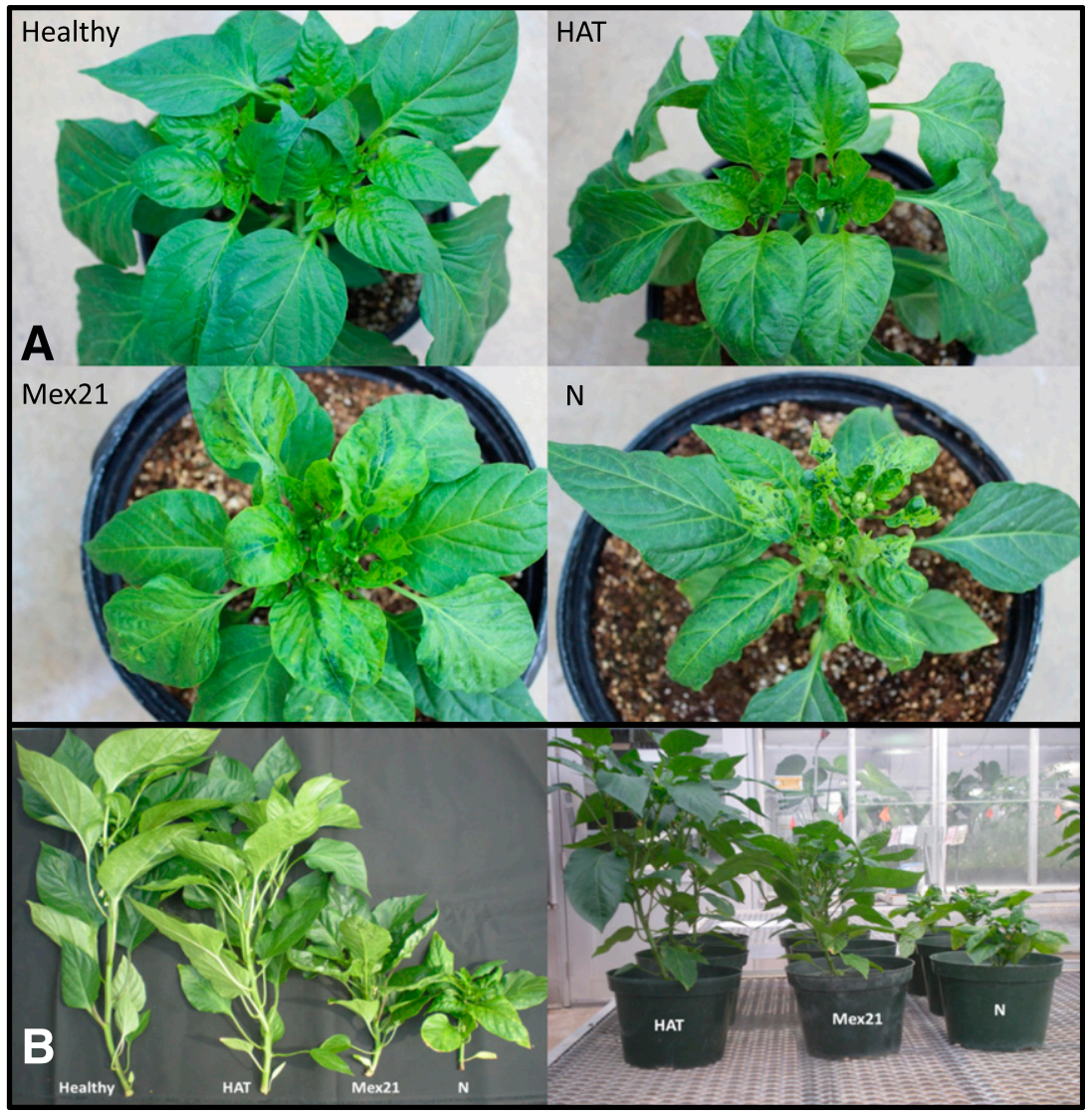

Fig. 1. Systemic symptoms induced in Calwonder pepper plants by Tobacco etch virus (TEV) strains HAT, Mex21, and N. A healthy control represented a mock-inoculation treatment consisting of buffer but no virus. A, Systemic foliar symptoms induced by each of the TEV strains. B, Effects on Calwonder plant growth by each of the TEV strains relative to a healthy control.
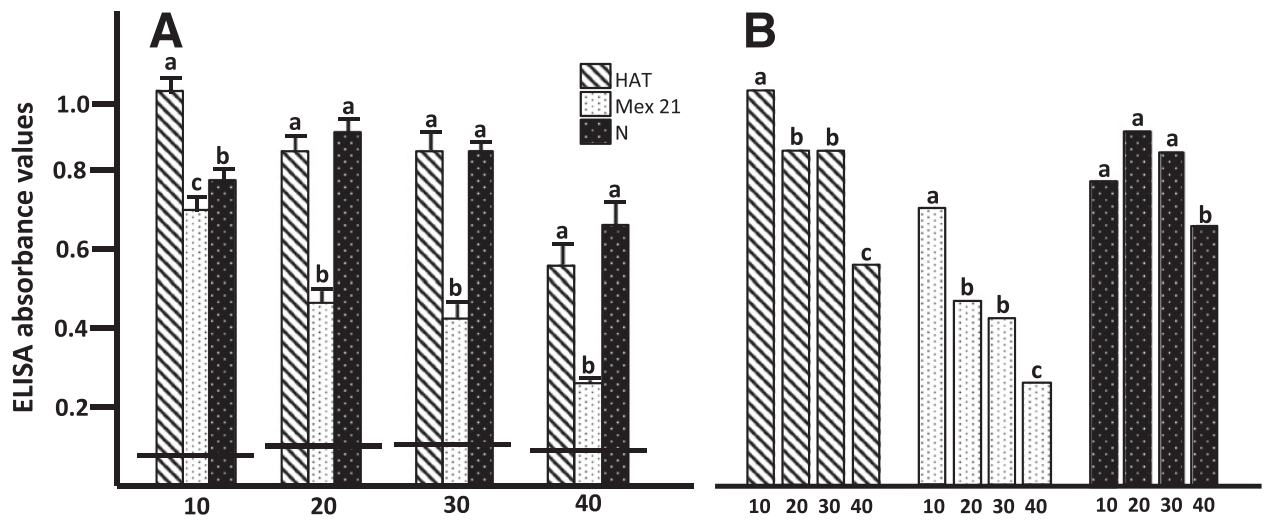

Days post-inoculation leaf samples tested

Fig. 2. Enzyme-linked immunosorbent assay (ELISA) absorbance values $(405 \mathrm{~nm})$ from systemically infected Calwonder pepper plant leaf tissues tested at $10,20,30$, and 40 days postinoculation. Plants were inoculated with Tobacco etch virus (TEV) strains HAT, Mex21, or N. A, Comparison among TEV strains at each sampling date. Horizontal lines represent the threshold for a positive ELISA reaction for the respective day of testing. B, Comparison within a TEV strain at different sampling dates. Bars represent the mean ELISA absorbance value \pm standard error; $n=20$ plants per treatment per time point. Treatments within a measurement date followed by the same letter are not significantly different $(P>0.05$; Kruskal Wallis test followed by Bonferroni multiple comparison of rank sums). 
At 10 dpi, samples from HAT-infected plants had a significantly higher mean ELISA absorbance value than samples from Mex21and $\mathrm{N}$-infected plants $\left(\chi^{2}=41.73, P<0.0001\right)$ (Fig. 2A). Also at $10 \mathrm{dpi}$, the mean ELISA value for $\mathrm{N}$-infected plants was significantly higher than that from Mex21-infected plants $(P=0.0035)$. At 20, 30, and $40 \mathrm{dpi}$, the mean ELISA absorbance values for HAT- and $\mathrm{N}$-infected plants did not differ from each other but both were significantly greater than for Mex21-infected plants. ELISA values within a TEV strain tended to decline over time (Fig. 2B). Plants infected with HAT $\left(\chi^{2}=47.07, P<0.0001\right)$ or Mex21 $\left(\chi^{2}=52.40, P<\right.$ 0.0001 ) had significant reductions in ELISA values from 10 to 20 and $30 \mathrm{dpi}$, with another significant reduction at $40 \mathrm{dpi}$ (Fig. 2B). In contrast, ELISA values for $\mathrm{N}$-infected plants were higher at 20 and 30 dpi compared with the 10-dpi value, although they did not differ significantly. Similar to the other virus treatments, there was a significant $\left(\chi^{2}=21.70, P<0.0001\right)$ decline for the ELISA absorbance value from $\mathrm{N}$-infected plants at 40 dpi.

It should be noted that the commercial ELISA kit used in this project was tested for its ability to detect each TEV strain. In four separate experiments using a range of different purified virus concentrations for each TEV strain to generate standard curves, the ELISA kit consistently reacted more strongly with Mex 21 , followed by HAT and then $\mathrm{N}$, although the differences were relatively minor (data not shown).

Effects on Calwonder growth. Plant height was measured the day of inoculation (prior to inoculation, $0 \mathrm{dpi}$ ) and at 10-day intervals through 40 dpi (Fig. 3). At 0 dpi, Calwonder plants in the HAT and $\mathrm{N}$ treatments were significantly shorter than the healthy control plants $(F=4.37, P=0.0071)$ but plant height among the TEV strain treatments did not differ (Fig. 3). At 10 dpi, 3 days after the onset of systemic symptoms, $\mathrm{N}$-infected plants were significantly shorter than HAT-infected plants and healthy controls but not different from

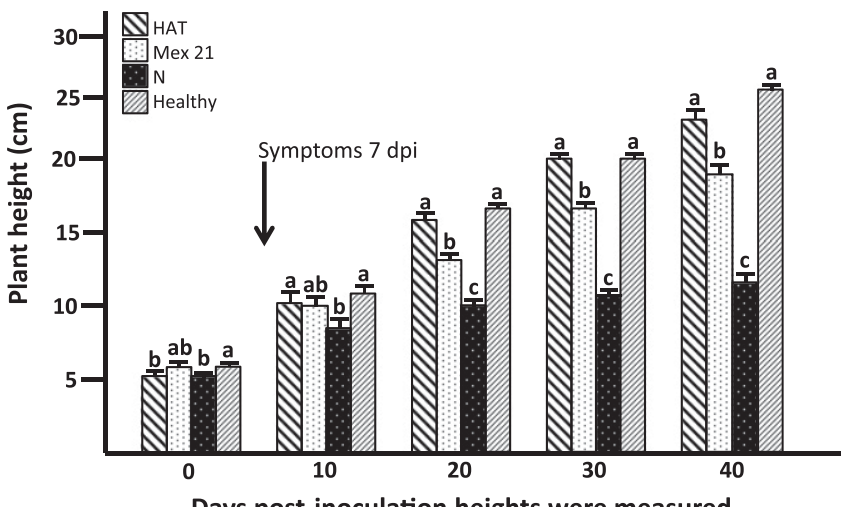

Fig. 3. Calwonder pepper plant heights (in centimeters) taken from the soil line to the tallest apical bud at 0 (day of inoculation), 10, 20,30, and 40 days postinoculation (dpi). Plants were inoculated with Tobacco etch virus strains HAT, Mex21, or $\mathrm{N}$ and compared with a healthy (mock-inoculated) control. The first appearance of systemic symptoms occurred by 7 dpi. Bars represent mean \pm standard error of plant height values; $n=18$ plants per treatment per time point. Treatments within a measurement date followed by the same letter are not significantly different $(P>$ 0.05 ; one-way analysis of variance followed by Tukey's test).
Mex21-infected plants $(F=7.18, P=0.0003)$. At 20,30 , and 40 dpi, N-infected plants were significantly shorter than those in the other treatments and Mex21-infected plants were significantly shorter than those in the HAT and healthy control treatments (Fig. $3)$. The HAT-infected plants did not differ from those in the healthy control treatment. The smaller size of HAT and N treatment plants at 0 dpi did not reflect or affect subsequent height measurements because HAT-infected plants did not differ from plants in the healthy control treatment through the remainder of the experiment.

As expected, effects of virus infection on internode length corresponded with effects on plant height. A difference in internode length occurred at a single location, between leaves 2 and 3 (I2-3), for HATinfected plants compared with healthy controls (Table 1). In all, 6 of 10 internodes along the main stem of Mex21-infected plants were shorter than those of healthy control plants, with 4 of these internodes also shorter than those of HAT-infected plants (including leaves 5 to 9 and internodes I5-6 through I8-9) (Table 1). Internodes of $\mathrm{N}$-infected plants were significantly shorter compared with all other treatments for leaves 3 through 10 (I3-4 through I9-10) (Table 1). The negative impact on internode extension for Mex21-infected plants, and especially for $\mathrm{N}$-infected plants, occurred at internodes below the leaves that initially expressed systemic symptoms (I5-6 and I6-7, Table 1). This suggests that invasion of growthcontrolling tissues such as the apical bud in the stem of Mex21and $\mathrm{N}$-infected plants had negative effects on tissues that expressed few or no symptoms (e.g., leaves 1 through 4 ) and occurred below tissues that were the first to express systemic symptoms.

Aboveground shoot fresh weight at $40 \mathrm{dpi}$ for $\mathrm{N}$-infected plants was significantly less than that for all other treatments, and Mex21-infected plants weighed significantly less than healthy control plants $(F=116.37, P<0.0001$; Fig. 4). HAT and healthy control treatments did not differ in their aboveground fresh weights. The root

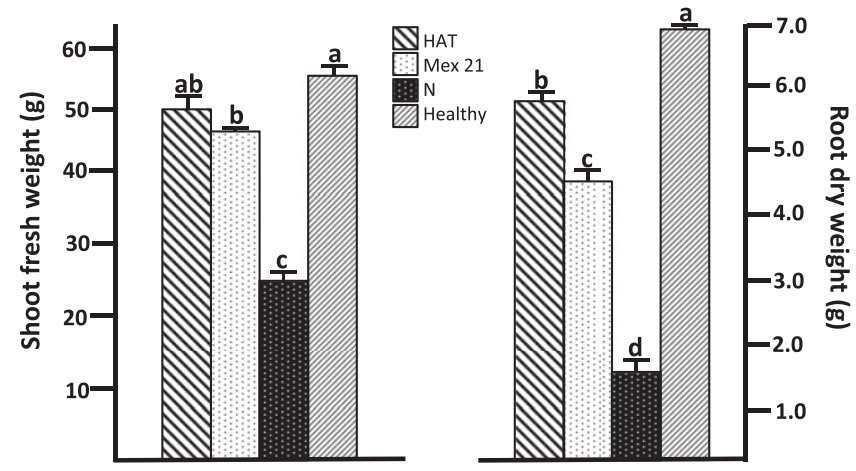

Fig. 4. Calwonder pepper plant aboveground (shoot) fresh weights (in grams) and root dry weights (in grams) taken at 40 days postinoculation (dpi) following inoculation with Tobacco etch virus strains HAT, Mex21, or N and compared with a healthy (mockinoculated) control. Bars represent mean \pm standard error of shoot and root weight values; $n=12$ plants per treatment for each growth parameter. Treatments within a growth parameter (aboveground fresh weight or root dry weight) followed by the same letter are not significantly different $(P>0.05$; one-way analysis of variance followed by Tukey's test).

Table 1. Internode lengths along the main stem of Calwonder pepper plants inoculated with Tobacco etch virus strains HAT, Mex21, or N and a healthy control

\begin{tabular}{lcccccccccc}
\hline & \multicolumn{10}{c}{ Internode $^{\mathbf{z}}$} \\
\cline { 2 - 11 } Treatment & H-L1 & $\mathbf{I 1 - 2}$ & $\mathbf{I 2 - 3}$ & $\mathbf{I 3 - 4}$ & $\mathbf{I 4 - 5}$ & $\mathbf{I 5 - 6}$ & $\mathbf{I 6 - 7}$ & $\mathbf{I 7 - 8}$ & $\mathbf{I 8 - 9}$ & $\mathbf{I 9 - 1 0}$ \\
\hline Healthy & $4.0 \pm 0.2 \mathrm{a}$ & $0.4 \pm 0.1 \mathrm{a}$ & $2.0 \pm 0.1 \mathrm{a}$ & $1.5 \pm 0.1 \mathrm{a}$ & $1.9 \pm 0.1 \mathrm{a}$ & $1.3 \pm 0.2 \mathrm{ab}$ & $2.2 \pm 0.2 \mathrm{a}$ & $1.8 \pm 0.2 \mathrm{a}$ & $1.6 \pm 0.2 \mathrm{a}$ & $1.3 \pm 0.2 \mathrm{a}$ \\
HAT & $3.9 \pm 0.2 \mathrm{a}$ & $0.4 \pm 0.1 \mathrm{a}$ & $1.6 \pm 0.1 \mathrm{~b}$ & $1.5 \pm 0.1 \mathrm{a}$ & $1.8 \pm 0.2 \mathrm{ab}$ & $1.5 \pm 0.1 \mathrm{a}$ & $2.3 \pm 0.1 \mathrm{a}$ & $1.6 \pm 0.1 \mathrm{a}$ & $1.3 \pm 0.2 \mathrm{ab}$ & $1.2 \pm 0.1 \mathrm{ab}$ \\
Mex 21 & $3.6 \pm 0.2 \mathrm{a}$ & $0.7 \pm 0.1 \mathrm{a}$ & $1.6 \pm 0.1 \mathrm{~b}$ & $1.2 \pm 0.1 \mathrm{a}$ & $1.4 \pm 0.1 \mathrm{~b}$ & $0.9 \pm 0.1 \mathrm{~b}$ & $1.2 \pm 0.1 \mathrm{~b}$ & $0.8 \pm 0.1 \mathrm{~b}$ & $0.8 \pm 0.1 \mathrm{c}$ & $0.9 \pm 0.2 \mathrm{~b}$ \\
N & $3.8 \pm 0.2 \mathrm{a}$ & $0.5 \pm 0.1 \mathrm{a}$ & $1.9 \pm 0.1 \mathrm{ab}$ & $0.8 \pm 0.1 \mathrm{~b}$ & $0.9 \pm 0.1 \mathrm{c}$ & $0.4 \pm 0.1 \mathrm{c}$ & $0.4 \pm 0.0 \mathrm{c}$ & $0.3 \pm 0.0 \mathrm{c}$ & $0.3 \pm 0.0 \mathrm{~d}$ & $0.3 \pm 0.0 \mathrm{c}$ \\
\hline
\end{tabular}

${ }^{\mathrm{z}}$ Internode designations are H-L1 (hypocotyl to leaf 1), I1-2 (internode between leaves 1 and 2), and each successive internode through I9-10 (internode between leaves 9 and 10). Values represent mean \pm standard error of internode length (in centimeters); $n=10$ plants per treatment. Internode length differences among plants treated with various virus strains within each internode segment were analyzed using one-way analysis of variance (ANOVA) after data were log transformed to fit the assumptions of ANOVA. Means were separated using Tukey's posthoc test. Means followed by the same letter in each column are not significantly different $(P>0.05)$. The boxed area represents the first leaves to express systemic symptoms. 
dry weight at $40 \mathrm{dpi}$ for each virus treatment was significantly less than that of the healthy control $(F=55.97, P<0.0001$; Fig. 4). There were significant differences for root dry weight among virus treatments. N-infected plant roots weighed less than roots of Mex21infected plants, which weighed less than those of HAT-infected plants (Fig. 4).

Effects on fruit yield. Fruit from healthy control plants and HATinfected plants were similar in appearance, although those from HAT-infected plants generally had less of the standard bell pepper block shape (Fig. 5A and B). All fruit from Mex21-infected plants were deformed, regardless of size, and most had chlorotic streaks that ran lengthwise on the fruit (Fig. 5C). All fruit produced on $\mathrm{N}$-infected plants were small and deformed, with pronounced chlorotic streaks (Fig. 5D).

Marketable fruit numbers did not differ for HAT-infected and healthy control plants (Table 2). In contrast, Mex21-infected plants produced only a single marketable fruit and no marketable fruit was collected from $\mathrm{N}$-infected plants. HAT-infected and healthy control plants produced 100 or more nonmarketable fruit with no significant difference among them (Table 2). Mex21-infected plants

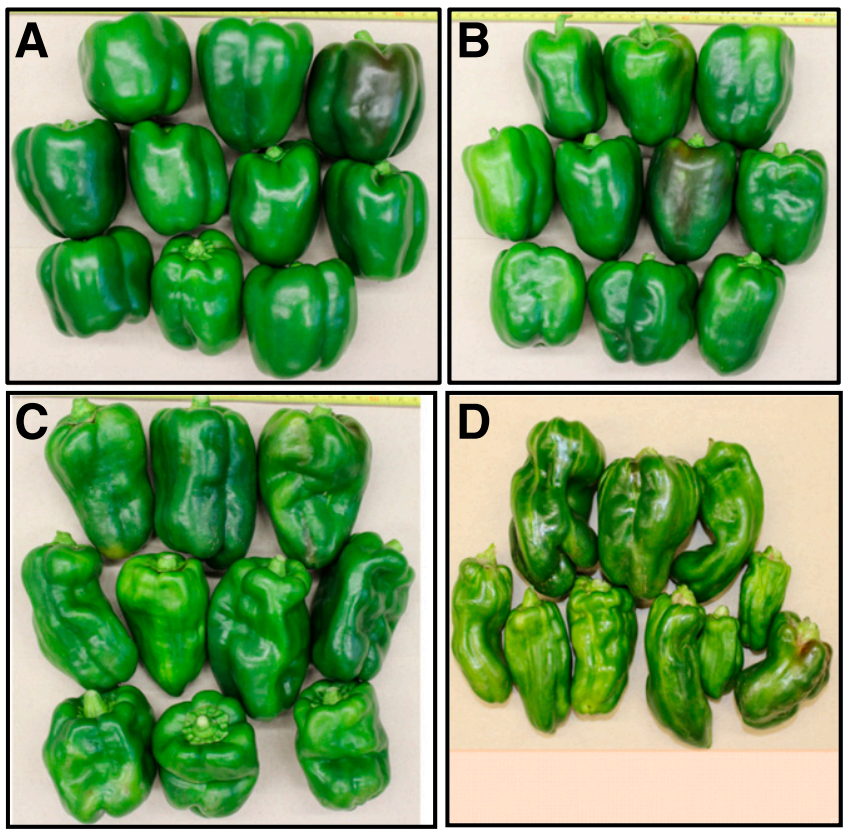

Fig. 5. Calwonder pepper plant fruit collected from treatments $A$, healthy control and plants infected with Tobacco etch virus strains B, HAT; C, Mex21; and D, N. produced significantly fewer nonmarketable fruit than HATinfected $\left(\chi^{2}=11.16, P=0.001\right)$ and healthy control $\left(\chi^{2}=15.06\right.$, $P=0.0001)$ plants, with $\mathrm{N}$-infected plants producing significantly fewer fruit than all other treatments. A similar trend occurred for total fruit numbers that weighed $50 \mathrm{~g}$ or more (Table 2). It should be noted that the large number of nonmarketable fruit for healthy control and HAT treatments was largely the result of being harvested prior to maturing because these fruit developed along branches that broke due to fruit weight. In contrast, all nonmarketable fruit collected from Mex21- and N-infected plants had some form of virus-induced discoloration or deformation.

Measurable marketable fruit weight was available only for HAT and healthy control treatments, with fruit from healthy control plants weighing significantly more than those from HAT-infected plants $(Z=-2.41, P=0.02)$ (Table 2). Mex21 and N treatments were eliminated from the analysis because Mex21-infected plants produced only a single marketable fruit while $\mathrm{N}$-infected plants did not produce any marketable fruit. Nonmarketable fruit weights did not differ among HAT, Mex21, and healthy control treatments; however, fruit from $\mathrm{N}$-infected plants weighed significantly less than those from Mex21-infected $(P=0.02)$ and healthy control $(P=0.03)$ plants. Total fruit weight for those weighing $50 \mathrm{~g}$ or more did not differ among HAT, Mex21, and healthy control treatments (Table 2).

\section{Discussion}

Genetic resistance in Capsicum spp. against various strains of TEV was documented at the whole-plant and protoplast levels, resistance alleles have been mapped, and, for several important sources of resistance, the Capsicum eIF4E protein was identified as the resistance allele (Deom et al. 1997; Kang et al. 2005; Murphy et al. 1998). Perez et al. (2012) generated chimera among TEV strains HAT, Mex21, and N whereby the HAT VPg was replaced by that from either Mex 21 or $\mathrm{N}$. They determined that it was the interaction between the viral VPg and the Capsicum eIF4E protein that resulted in a susceptible or resistant response to virus inoculation. More recently, the nucleotide sequence among the three TEV strains revealed $91 \%$ identity for HAT with Mex 21 and $\mathrm{N}$ and $98 \%$ identity among Mex21 and N (Velasquez et al. 2015). Despite their use in important genetic studies, the TEV strains HAT, Mex21, and N have not been evaluated comparatively for their pathogenicity on pepper. Therefore, a well-established susceptible pepper variety, Calwonder, was used to comparatively describe disease symptoms (type and severity) and effect on different plant growth parameters in response to infection by HAT, Mex21, or N.

The initial systemic symptom, vein-clearing, occurred at essentially the same time for plants infected with each of the three TEV strains, although it varied in intensity and duration. For instance, it appeared more pronounced for plants infected with Mex 21 and $\mathrm{N}$

Table 2. Calwonder fruit counts and weights for plants infected with Tobacco etch virus (TEV) strains HAT, Mex21, or N as well as a healthy control ${ }^{\mathrm{w}}$

\begin{tabular}{|c|c|c|c|c|c|c|}
\hline \multirow[b]{2}{*}{ Treatment $^{\mathrm{z}}$} & \multicolumn{3}{|c|}{ Fruit count $^{\mathrm{x}}$} & \multicolumn{3}{|c|}{ Fruit weight $(g)^{y}$} \\
\hline & Market & Nonmarket & Total $(\geq 50 \mathrm{~g})$ & Market & Nonmarket & Total $(\geq 50 \mathrm{~g})$ \\
\hline HAT & $21 \mathrm{a}$ & $100 \mathrm{a}$ & $79 a$ & $117.0 \pm 3.6 \mathrm{~b}$ & $57.2 \pm 2.7 \mathrm{ab}$ & $86.4 \pm 2.9 \mathrm{a}$ \\
\hline Mex21 & $1 \mathrm{~b}$ & $58 \mathrm{~b}$ & $38 \mathrm{~b}$ & - & $66.6 \pm 3.6 \mathrm{a}$ & $83.8 \pm 3.3 \mathrm{a}$ \\
\hline $\mathrm{N}$ & $0 \mathrm{~b}$ & $3 \mathrm{c}$ & $0 \mathrm{c}$ & - & $21.3 \pm 3.6 \mathrm{~b}$ & - \\
\hline Healthy & $26 \mathrm{a}$ & $108 \mathrm{a}$ & $93 \mathrm{a}$ & $132.5 \pm 4.4 \mathrm{a}$ & $62.9 \pm 2.5 \mathrm{a}$ & $94.2 \pm 3.2 \mathrm{a}$ \\
\hline
\end{tabular}

${ }^{\mathrm{w}}$ Fruit yields (count and weight) were determined and graded marketable (Market) or nonmarketable (Nonmarket) according to United States Department of Agriculture standards (USDA 1991).

$x$ Values represent actual fruit count (number of observations). The deviation of marketable or nonmarketable fruit counts among the four treatments from hypothesized equal proportions $(25 / 25 / 25 / 25 \%)$ was analyzed using an exact $\chi^{2}$ goodness-of-fit test. Pairwise comparison was made using a similar $\chi^{2}$ test (50/50\%) with Bonferroni adjustment to $P$ value. Counts followed by the same letter in each column are not significantly different $(P>0.05)$.

y Values represent mean \pm standard error of fruit weight (in grams); - indicates treatment data not included in analysis due to low number of samples or complete lack of sample. For marketable fruit weight, the difference in fruit weight between HAT and Healthy treatments was analyzed using the Wilcoxon-Mann-Whitney test. Means followed by the same letter are not significantly different $(P>0.05)$. Marketable fruit weight for plants infected with Mex21 or N was excluded from the analysis due to lack of samples. Difference in nonmarketable fruit weight among treatments was analyzed using the Kruskal-Wallis test. Means were separated using Bonferroni multiple comparison of rank sums of fruit weights. Means followed by the same letter are not significantly different $(P>0.05)$. Difference in total yield for fruit that weighed $50 \mathrm{~g}$ or more among treatments was analyzed using the Kruskal-Wallis test. The virus treatment $\mathrm{N}$ was excluded from the analysis because of extremely low sample size.

z Treatments included TEV strains HAT, Mex21, and $\mathrm{N}$ along with a healthy control treatment. 
than for those infected with HAT, and the vein-clearing symptom remained visible for $\mathrm{N}$-infected plants well after it was no longer visible for Mex21- and especially HAT-infected plants. Despite a similar initial systemic symptom, subsequent disease symptoms differed and clearly distinguished the three TEV strains. Overall, disease symptom severity in Calwonder plants ranged from mild (HAT) to moderate $(\operatorname{Mex} 21)$ to severe $(\mathrm{N})$.

The effects on plant growth corresponded with the disease severity caused by each TEV strain. HAT-infected plants expressed mild systemic symptoms and did not differ from the healthy control plants in plant height, including internode lengths along the main stem and aboveground plant fresh weight. Root dry weight was the only growth parameter for which HAT-infected plants differed from the healthy control. Mex21-infected plants had more severe symptoms than HAT-infected plants and their growth was more severely affected. For example, plant height (at 20, 30, and 40 dpi) and root dry weight were significantly less for Mex21-infected plants than for HAT-infected and healthy control plants, while aboveground plant fresh weight was significantly less than for the healthy control. Also, the internodes encompassing leaves 4 to 10 were shorter for Mex21-infected plants than HAT-infected plants or healthy control plants and, in some cases, both treatments. N-infected plants were significantly negatively affected relative to each of the other treatments for plant height, aboveground plant fresh weight, root dry weight, and internode lengths encompassing leaves 3 to 10 . Viral effects on fruit production were somewhat complicated by the high number of nonmarketable fruit for HAT and healthy control treatments due to premature harvest. In a similar trend for disease symptoms, however, Mex21-infected plants produced a relatively large number of fruit but these were mostly nonmarketable due to deformation and discoloration. $\mathrm{N}$-infected plants were severely diseased and, consequently, produced few fruit, all of which were small, deformed, and discolored.

All three virus strains moved through the stem and into young uninoculated leaves at approximately the same rate with a similar initial result (i.e., systemic vein-clearing symptoms). The impact on internode extension, however, varied among the TEV strains, with significant reductions in internode extension for Calwonder plants infected with Mex21 and $\mathrm{N}$ but not for HAT-infected plants. The data in Table 1 show length of internodes along the main stem of Calwonder plants; however, they correspond strongly with effects on growth above the main stem for secondary and tertiary branches as well as leaves associated with those branches. Above the branching point of the main stem, HAT-infected plants had stem lengths and leaf sizes similar to those of healthy control plants. In contrast, stems and leaves above the main stem for Mex21- and $\mathrm{N}$-infected plants were stunted in size, and leaves expressed varied amounts of deformation. Growth above the main stem of $\mathrm{N}$-infected plants was minimal, with short stems and many small leaves bunched together at the top of each plant. These negative effects on growth are likely associated with effects on growth-related factors such as hormones, their production or distribution, or both. This effect on plant growth factors that led to reduced internode extension below the first leaves to express systemic symptoms (for Mex21- and $\mathrm{N}$-infected plants) indicates that the initial invasion of the apical region of the stem by Mex 21 or $\mathrm{N}$ altered growth processes at lower stem segments when virus was in the process of invading noninoculated leaves that occurred above those stem segments. In contrast, this effect on growth was not observed for HAT-infected plants despite a similar distribution of virus in the stem and at similar time frames.

Effects of virus infection on plant growth have been reviewed (Culver and Padmanabhan 2007; Jameson and Clarke 2002; Revers and García 2015) with respect to effects on plant hormone production and distribution as well as effects on photosynthesis and other physiological processes. Although effects on Calwonder physiology were not determined in the present study, it is plausible to expect measurable differences among the TEV strains, considering their differences in disease severity and effects on plant growth. It has been suggested that potyviruses replicate in chloroplasts (Revers and García 2015). Despite the differences in disease severity among the three TEV strains and associated effects on Calwonder growth (especially the extensive stunting and chlorosis induced by $\mathrm{N}$ ), the lack of corresponding levels of virus accumulation in systemically infected leaves was not anticipated. The similar amount of HAT and N detected, along with the significantly lower level of Mex21 detected, did not correlate with symptom severity. Apparently, the lack of correlation between disease severity and virus accumulation is not uncommon (Carrasco et al. 2007; Escriu et al. 2000; Stewart et al. 2005) and was illustrated with HAT, Mex21, and N in Nicotiana spp. (Velasquez et al. 2015). The varied responses of Nicotiana spp. to the TEV strains and lack of associated correlation with virus accumulation levels (Velasquez et al. 2015) agrees with findings by Lalić et al. (2011), indicating that TEV fitness in one host informs little about viral fitness in another host.

A study underway has generated a transcriptome to each TEV strain in Calwonder, and the differences in gene expression closely reflect the differences in disease severity and effect on Calwonder growth (J. F. Murphy, unpublished). Identification of the viral determinants involved with each TEV strain's pathogenicity in conjunction with identification of host genes affected by infection will allow focused studies to dissect the pathways by which each TEV strain induces its respective disease in a susceptible host such as Calwonder.

\section{Acknowledgments}

We thank J. Farr and M. Foshee for their assistance at the Plant Science Greenhouse Facility.

\section{Literature Cited}

Allison, R., Johnston, R. E., and Dougherty, W. G. 1986. The nucleotide sequence of the coding region of tobacco etch virus genomic RNA: Evidence for the synthesis of a single polyprotein. Virology 154:9-20.

Anderson, C. W., and Corbett, M. K. 1957. Virus diseases of peppers in central Florida survey results 1955. Plant Dis. Rep. 41:143-147.

Andrianifahanana, M., Lovins, K., Dute, R., Sikora, E., and Murphy, J. F. 1997. Pathway for phloem-dependent movement of pepper mottle potyvirus in the stem of Capsicum annuum. Phytopathology 87:892-898.

Berger, P. H., Adams, M. J., Barnett, O. W., Brunt, A. A., Hammond, J., Hill, J. H., Jordan, R. L., Kashiwazaki, S., Rybicki, E., Spence, N., Stenger, D. C., Ohki, S. T., Uyeda, I., van Zaayen, A., Valkonen, J., and Vetten, H. J. 2005. Pages 819-884 in: Virus Taxonomy. 8th Report of the International Committee on Taxonomy of Viruses. C. M. Fauquet, M. A. Mayo, J. Maniloff, U. Desselberger, and L. A. Ball, eds. Elsevier, Amsterdam.

CABI. 2010. Tobacco etch virus. Map 1094 in: Distribution maps of plant diseases. CABI, Wallingford, U.K.

Carrasco, P., de la Iglesia, F., and Elena, S. F. 2007. Distribution of fitness and virulence effects caused by single-nucleotide substitutions in Tobacco etch virus. J. Virol. 81:12979-12984.

Culver, J. N., and Padmanabhan, M. S. 2007. Virus-induced disease: Altering host physiology one interaction at a time. Annu. Rev. Phytopathol. 45: 221-243.

Deom, C. M., Murphy, J. F., and Pagiuo, O. 1997. Inhibition of tobacco etch virus replication in Capsicum annuum. Mol. Plant-Microbe Interact. 10:917-921.

Edwardson, J. R., and Christie, R. G. 1997. Viruses Infecting Pepper and Other Solanaceous Crops, Vol. I and II. University of Florida, Gainesville.

Escriu, F., Fraile, A., and García-Arenal, F. 2000. Evolution of virulence in natural populations of the satellite RNA of Cucumber mosaic virus. Phytopathology 90:480-485.

Green, S. K., and Kim, J. S. 1991. Characteristics and control of viruses infecting peppers: A literature review. AVRDC Tech. Bull. No.18.

Hari, V., Siegel, A., Rozek, C., and Timberlake, W. E. 1979. The RNA of tobacco etch virus contains poly(A). Virology 92:568-571.

Jameson, P., and Clarke, S. 2002. Hormone-virus interaction in plants. Crit. Rev. Plant Sci. 21:205-228.

Kang, B.-C., Yeam, I., Frantz, J. D., Murphy, J. F., and Jahn, M. M. 2005. The pvr1 locus in Capsicum encodes a translation initiation factor eIF4e that interacts with Tobacco etch virus VPg. Plant J. 42:392-405.

Lalić, J., Cuevas, J. M., and Elena, S. F. 2011. Effect of host species on the distribution of mutational fitness effects for an RNA virus. PLoS Genet. 7:e1002378.

Murphy, J. F. 2012. Three Tobacco etch virus strains that induce distinctly different disease phenotypes. Phytopathology 102:S4.84.

Murphy, J. F. 2014. Effects on bell pepper fruit yield by infection of each of three strains of Tobacco etch virus (TEV). Phytopathology 104:S3.84.

Murphy, J. F., Blauth, J. R., Livingstone, K. D., Lackney, V., and Jahn, M. K. 1998. Genetic mapping of the pvrl locus in Capsicum spp. and evidence that distinct potyvirus resistance loci control responses to two potyviruses that differ at the whole plant and cellular levels. Mol. Plant-Microbe Interact. 11: 943-951. 
Murphy, J. F., Rhoads, R. E., Hunt, A. G., and Shaw, J. G. 1990. The VPg of tobacco etch virus RNA is the $49-\mathrm{kDa}$ proteinase or the N-terminal $24-\mathrm{kDa}$ part of the proteinase. Virology 178:285-288.

Murphy, J. F., Wojciech, R., Rhoads, R. E., Hunt, A. G., and Shaw, J. G. 1991. A tyrosine residue in the small nuclear inclusion protein of tobacco vein mottling virus links the VPg to the viral RNA. J. Virol. 65:511-513.

Nutter, F. W., Kuhn, C. W., and All, J. N. 1989. Models to estimate yield losses in bell pepper caused by tobacco etch virus epidemics. Phytopathology 79:1213-1215.

Ozaki, H. Y. 1963. Pepper variety trials on the sandy soils of the lower east coast. Proc. Fla. State Hortic. Soc. 76:228-232.

Perez, K., Yeam, I., Kang, B.-C., Ripoll, D. R., Kim, J., Murphy, J. F., and Jahn, M. M. 2012. Tobacco etch virus infectivity in Capsicum spp. is determined by a maximum of three amino acids in the viral virulence determinant VPg. Mol. Plant-Microbe Interact. 25:1562-1573.

Purcifull, D. E., and Hiebert, E. 1982. Tobacco etch virus. CMI/AAB Description of Plant Viruses No. 258, Association of Applied Biologists, Wellesbourne, Warwickshire, U.K.

Revers, F., and García, J. A. 2015. Molecular biology of potyviruses. Adv. Virus Res. 92:101-199.

Roberts, P. D., Adkins, S., Pernezny, K., and Jones, J. B. 2004. Diseases of pepper and their management. Pages 33-387 in: Diseases of Fruits and Vegetables, Vol. II. S. A. M. H. Naqvi, ed. Kluwer Academic Publishers, Dordrecht, The Netherlands.
Rufty, R. C., Miller, R. D., and Gooding, G. V., Jr. 1989. Effect of tobacco etch and tobacco vein mottling virus on yield of burley tobacco genotypes. Plant Dis. 73 : 45-48.

Shukla, D. D., Ward, C. W., and Brunt, A. A. 1994. Potyviruses: Biology, Molecular Structure and Taxonomy. CAB International, Wallingford, England.

Stewart, A. D., Logsdon, J. M. Jr, and Kelley, S. E. 2005. An empirical study of the evolution of virulence under both horizontal and vertical transmission. Evolution 59:730-739.

Urcuqui-Inchima, S., Haenni, A. L., and Bernardi, F. 2001. Potyvirus proteins: A wealth of functions. Virus Res. 74:157-175.

USDA. 1991. United States Department of Agriculture Standards for Grades of Sweet Bell Peppers. Online publication: http://www.ams.usda.gov/gradesstandards/sweet-peppers-grades-and-standards

Van de Vooren, J., Welles, G. W. H., and Hayman, G. 1986. Glasshouse crop production. Pages 581-623 in: The Tomato Crop. A Scientific Basis for Improvement. J. G. Atherton and J. Rudich, eds. Chapman and Hall, London.

Velasquez, N., Hossain, M. J., and Murphy, J. F. 2015. Differential disease symptoms and full-length genome sequence analysis for three strains of Tobacco etch virus. Virus Genes 50:442-449.

Velasquez, N., and Murphy, J. F. 2014. A Tobacco etch virus NW isolate that overcomes $p v r 1$ and $p v r 1^{2}$ resistance in Capsicum sp. Plant Pathol. 63:675-683.

Zitter, T. A. 1971. Virus diseases of pepper in South Florida. Proc. Fla. State Hortic. Soc. 84:177-183. 